\title{
Enhanced Development of Atherosclerosis in Cholesterol-fed Rabbits by Suppression of Cell-mediated Immunity
}

\author{
Simon E. Roselaar, * Gustav Schonfeld, * and Alan Daugherty * \\ *Department of Medicine and ${ }^{\ddagger}$ Department of Biochemistry and Molecular Biophysics, Washington University School of Medicine, \\ St. Louis, Missouri 63110
}

\begin{abstract}
T lymphocytes are present in atherosclerotic lesions, but the role of this cell type in the disease process has not been determined. To determine whether cell-mediated immunity influences atherogenesis, New Zealand White rabbits fed a cholesterol-supplemented diet $(0.5 \% \mathrm{wt} / \mathrm{wt})$ were treated with cyclosporin A $(n=20)$ or vehicle alone $(n=16)$ for 12 wk. The dose of cyclosporin $A$ was adjusted so that a blood concentration between 100 and $200 \mathrm{ng} / \mathrm{ml}$ was maintained to achieve a selective action on T-lymphocytes. Effectiveness of immunosuppression in cyclosporin A-treated rabbits was confirmed by allogeneic skin graft survival. Cyclosporin A administration did not affect total plasma lipid concentrations, body weight, or renal function. Percentage of aortic intimal area covered with atherosclerotic lesions was increased significantly by immunosuppression in both the arch region $(75 \pm 3 \%$ [mean \pm SEM] compared with $60 \pm 5 \%$ in controls; $P<0.01$ ) and the thoracic region $(47 \pm 7 \%$ vs $27 \pm 6 \% ; P=0.04)$. Enhanced atherogenesis was not associated with diminished numbers of $T$ lymphocytes in lesions, changes in $\mathbf{T}$ lymphocyte subtype, or any discernible change in cellular composition. Humoral immune responses to oxidized LDL were similar in the two groups: serum titres of autoantibodies against malondialdehyde-modified LDL were equivalent. These data demonstrate that cyclosporin A-induced suppression of cell-mediated immunity increased the development of macrophage-rich atherosclerotic lesions in cholesterol-fed rabbits. (J. Clin. Invest. 1995. 96:1389-1394.) Key words: atherosclerosis - cyclosporin A - T lymphocytes • immunosuppression - autoantibodies
\end{abstract}

\section{Introduction}

T lymphocytes are constituents of atherosclerotic lesions at all stages of development (1-3). Since T lymphocytes are important effectors of cell-mediated immunity, there is increasing interest in the role of the immune system in the development of atherosclerosis. Abundance of $\mathrm{T}$ lymphocytes varies in lesions in different regions, but they may constitute up to $20 \%$

Address correspondence to Alan Daugherty, Box 8086, Cardiovascular Division, Washington University School of Medicine, 660 South Euclid Avenue, St. Louis, MO 63110. Phone: 314-362-3517; FAX: 314-3627657; E-mail: doco@imgate.wustl.edu.

Received for publication 21 November 1994 and accepted in revised form 19 May 1995.

J. Clin. Invest.

(C) The American Society for Clinical Investigation, Inc. 0021-9738/95/09/1389/06\$2.00

Volume 96, September 1995, 1389-1394 of cells in the fibrous cap of advanced human lesions (4). Lymphocytes are present in all lesions, even those in the early stages of development, in rabbits fed a high-cholesterol diet (5). Both helper $\left(\mathrm{CD}^{+}\right)$and suppressor $\left(\mathrm{CD8}^{+}\right) \mathrm{T}$ lymphocytes are present in human lesions $(6,7)$, while in rabbit lesions the CD4+ phenotype predominates (5). Immunocytochemical demonstration of MHC class II indicates that $\mathrm{T}$ lymphocytes in lesions are immunologically activated (8) and polyclonal in origin (9).

There is abundant evidence for the presence of lymphocytes within atherosclerotic lesions, but the specific role of the immune system in atherogenesis has not been defined. T-lymphocytes elaborate many cytokines and growth factors that interact with smooth muscle cells and macrophages (10), the two major cell types present within atherosclerotic lesions. T lymphocytesecreted cytokines may exert a variety of effects, including modulation of cell migration and proliferation, and deposition of lipoprotein-cholesterol. The ability of $\mathrm{T}$ lymphocytes to secrete cytokines and their presence from the early through the late stages of lesion development indicate a likely impact of this cell on atherogenesis. Modulation of immune function in animals with atherosclerosis provides a model with which to directly address this question.

To determine whether suppression of cell-mediated immunity affects the development of lipid-laden macrophage-based atherosclerotic lesions, we examined the effect of immunosuppression with cyclosporin A (CyA). ${ }^{1} \mathrm{CyA}$ binds to cyclophilin $A$, preventing transcription of $\mathrm{IL}-2$ and resulting in inhibition of T helper lymphocyte activation (11). CyA also inhibits synthesis of IFN- $\gamma$, IL-3, IL-4, TNF- $\alpha$ and granulocyte macrophage colony-stimulating factor by $\mathrm{T}$ lymphocytes (12). CyA has the potential to exert many nonspecific effects if blood concentrations are not adequately controlled. However, $\mathrm{T}$ lymphocytes are exceptionally sensitive to CyA, so that they are affected by concentrations of the drug not likely to trigger nonspecific effects (13). At blood concentrations sufficient to prevent MHCincompatible skin allograft rejection without overt toxicity or changes in plasma lipid concentrations, suppression of cellmediated immunity is associated with increased severity of aortic atherosclerosis in cholesterol-fed rabbits.

\section{Methods}

Animals. Male New Zealand White rabbits, 2-3 mo old, were obtained from Myrtles Rabbit Farm (Thompson Station, TN) and housed in separate cages in specific pathogen-free rooms maintained on a $12-\mathrm{h}$ light/dark cycle. Water was available ad lib. After a 2-wk period on a normal laboratory diet animals were placed on a diet containing $0.5 \%$ (wt/wt) cholesterol (cat. No. 5731C-T; Purina Test Diets, Richmond,

1. Abbreviations used in this paper: CyA, cyclosporin A; MDA, malondialdehyde. 
IN), 120 grams/d for $12 \mathrm{wk}$. They were inspected daily for general health and weighed weekly. All procedures were approved by the Washington University Animal Studies Committee.

Administration of cyclosporin A. CyA was a generous gift from Sandoz Inc., (East Hanover, NJ). The drug was dissolved in $100 \%$ ethanol (1 gram $/ \mathrm{ml}$ ), diluted with olive oil (Humco, Texarkana, TX) to give a final concentration of $100 \mathrm{mg} / \mathrm{ml}$, and sterilized by filtration $(0.22 \mu \mathrm{m})$. Dosage was $20 \mathrm{mg} / \mathrm{kg}$ per $\mathrm{d}$ for the first week, then $\sim 20$ $\mathrm{mg} / \mathrm{kg}$ twice weekly, adjusted to maintain blood concentrations between 100 and $200 \mathrm{ng} / \mathrm{ml}$ (14). Drug administration and the atherogenic diet commenced at the same time. Drug was administered subcutaneously to sites on the upper back $(n=20)$. Control animals $(n=16)$ received an equal volume of $90 \%$ olive oil, $10 \%$ ethanol.

Measurement of cyclosporin A concentrations. Samples of whole blood were collected from the marginal ear vein of each rabbit into EDTA-containing Vacutainer (Becton Dickson Vacutainer Systems, Franklin Lakes, $\mathrm{NJ}$ ) tubes and was stored at $4^{\circ} \mathrm{C}$ until analysis. Whole blood concentrations of CyA were measured with a radioimmunoassay sensitive to $25 \mathrm{ng} / \mathrm{ml}$ (Incstar Corp., Stillwater, MN). 1 wk after treatment began, a blood sample was drawn $24 \mathrm{~h}$ after CyA was given. For all subsequent evaluations samples were drawn $72 \mathrm{~h}$ after drug administration.

Measurement of plasma lipoprotein-cholesterol distribution, lipids, and creatinine. Blood anticoagulated with EDTA $(1 \mathrm{mg} / \mathrm{ml})$ was centrifuged at $2,500 \mathrm{rpm}$ for $5 \mathrm{~min}$ to separate plasma. Plasma concentrations of total cholesterol, triglycerides, and phospholipids were determined by use of an enzyme-based colorimetric assay (Wako Chemical Co., Richmond, VA). Lipoprotein-cholesterol distributions were obtained for eight rabbits in each group by use of fast performance liquid chromatography, as described previously (15). Serum creatinine was measured with commercially available kits (Sigma Chemical Co., St. Louis, MO).

Skin graft survival. $9 \mathrm{wk}$ after the start of the study, full-thickness skin grafts $(2 \times 2 \mathrm{~cm})$ from Dutch-belted rabbits (Myrtles Rabbit Farm) were transferred from a single donor to five CyA-treated and five control New Zealand White rabbits under a full surgical aseptic technique. Grafts were secured with 6-0 nylon sutures onto the backs of recipients. Donor and recipient animals were anesthetized with intramuscular ketamine $(40 \mathrm{mg} / \mathrm{kg})$ and xylazine $(20 \mathrm{mg} / \mathrm{kg})$. Grafts were inspected daily for signs of necrosis and the results were recorded photographically.

Quantification of severity of aortic atherosclerosis. Animals were killed with sodium pentobarbital ( $150 \mathrm{mg} / \mathrm{kg}$ intravenously) $12 \mathrm{wk}$ after beginning the cholesterol-enriched diet; their aortae were excised from the aortic valve to the ileal bifurcation. Extraneous adventitia was removed. Aortae were placed on ice, opened longitudinally, pinned on wax, and intimal surfaces were photographed. Segments from the arch and midthoracic regions were fixed in paraformaldehyde ( $4 \% \mathrm{wt} / \mathrm{vol})$ and saline $(0.85 \% \mathrm{wt} / \mathrm{vol})$ or embedded in OCT compound (Miles Inc., Elkhart, IN) and frozen in liquid nitrogen. Remaining sections of arch and thoracic aorta were split longitudinally and each half was frozen at $-80^{\circ} \mathrm{C}$ for subsequent analyses of cholesterol content. The entire abdominal aorta was frozen. Severity of atherosclerosis was defined as the percent aortic intimal area covered with grossly discernible lesions as quantified with computerized planimetry (SigmaScan; Jandel Scientific, San Rafael, CA) as described previously (16). Percent intimal surface covered by atherosclerotic lesions was determined by two observers, one of whom was blinded to the experimental design. For analytical purposes, the arch was defined as the region of aorta between the aortic valve and the uppermost intercostal artery, the thoracic aorta that from the first to the eighth intercostal artery, and the abdominal aorta that from the eighth intercostal to the ileal bifurcation.

Cholesterol content of aortae. Tissue was minced with a razor blade and total lipids were extracted with chloroform-methanol (17), with addition of $5 \alpha$-cholestane as an internal standard. Lipids were dried under nitrogen and resuspended in methylene chloride; unesterified cholesterol was then measured by gas chromatography. The remaining sample was dried under nitrogen, saponified with tetramethylammonium hydroxide, and derivatized with tetrachloroethylene-methylbutyrate. Total cholesterol was extracted with chloroform-methanol and analyzed by gas chromatography (18). Completeness of saponification was determined with cholesteryl oleate and found to be linear over a range $>0.1-$ $10 \mathrm{mg} / \mathrm{ml}$.

Immunocytochemical analyses of lesions. Tissue was either frozen in OCT and sectioned with a cryostat or immersed in freshly prepared 4\% paraformaldehyde, paraffin-embedded, and sectioned on a microtome. Macrophages and smooth muscle cells were detected with the use of monoclonal antibodies RAM11 and HHF35 (Dako Corp., Carpinteria, CA), respectively, on paraffin-embedded sections. Frozen sections were immunostained for T-lymphocytes with L11/135 (Serotec Ltd., Kidlington, United Kingdom). Monoclonal antibodies KEN-4 and MU1-A (Spring Valley, Woodbine, MD) were used to distinguish CD4+ and $\mathrm{CD} 8+\mathrm{T}$ lymphocytes, respectively. MHC class II molecules were detected with monoclonal antibody $2 \mathrm{C} 4$ (Biosource International, Camarillo, CA). Immunocytochemistry was performed with a Fisher Microprobe system and Vectastain Elite $\mathrm{ABC}$ kits (Vector Laboratories, Inc., Burlingame, CA). Immunoreactivity was visualized by use of 3-amino 9-ethyl carbazole (Biomeda, Foster City, CA), which forms a red precipitate.

Specific cell types in atherosclerotic lesions were quantified with an image analysis system consisting of a microscope (Optiphot 2; Nikon Inc., Melville, NY) attached to a high-resolution camera (JE3462; Javelin Electronics, Torrance, $\mathrm{CA}$ ) and a personal computer equipped with a Coreco-Oculus OC-TCX frame grabber (Coreco, Saint-Laurent, Canada) and a high-resolution monitor. Computerized color image analysis was performed with Image-Pro Plus software (Media Cybernetics, Silver Spring, MD).

Detection of autoantibodies to malondialdehyde-modified LDL. Titres of autoantibodies to malondialdehyde (MDA)-modified LDL were determined in six randomly selected rabbits in each group with a microtitre plate enzyme-linked immunosorbent assay. MDA-LDL was synthesized as described by Haberland et al. (19) by use of LDL from a Watanabe heritable hyperlipidemic rabbit. 96-well microtitre plates (Nunc Inc., Naperville, IL) were coated with MDA-LDL unmodified LDL (both $10 \mu \mathrm{g} / \mathrm{ml}$ ), or PBS. After washing and blocking with 3\% bovine serum albumin (BSA; $30 \mathrm{mg} / \mathrm{ml}$ in PBS), duplicate wells were incubated with rabbit serum overnight at $4^{\circ} \mathrm{C}$ at dilutions of 1 in 300 to 1 in 100,000 in $1 \%$ BSA. Antibody binding was detected with a biotin-conjugated goat anti-rabbit secondary antibody, and conjugation with avidin (Vector Laboratories, Inc.); it was made visible with 2,2' azino-bis (3-ethylbenzthiazoline 6-sulfonic acid) diammonium, which forms a green color. Absorbance was read on an automated plate reader and titre of antibodies was expressed as absorbance of MDA-LDL binding minus that of LDL binding.

Statistical analyses. All statistical analyses were performed with SigmaStat for Windows (Jandel Scientific) software. Statistical differences between groups were sought for most parameters by Student's $t$ tests (two-way) after testing of the data for the appropriateness of use of this parametric test. Fisher's exact test was used to test for statistical differences in skin graft survival.

\section{Results}

Animals in the two groups had comparable weight gains throughout the study, and no animals showed abnormalities in their general health. Weight gain was $707 \pm 80$ grams $(n=20)$ in drug-treated animals and $848 \pm 81$ grams $(n=16)$ in control animals $(P=\mathrm{NS})$.

Maintenance of CyA concentrations in blood that were sufficient to suppress cell-mediated immunity, but that were not toxic, were critical to interpretation of this study. High concentrations of CyA cause nephrotoxicity, hypertension, and alterations in lipoprotein concentrations. Preliminary studies with CyA confirmed reports of poor absorption with enteral administration to rabbits (14), and no CyA was detectable in blood at doses of up to $10 \mathrm{mg} / \mathrm{kg}$ per $\mathrm{d}$. Therefore, CyA was adminis- 


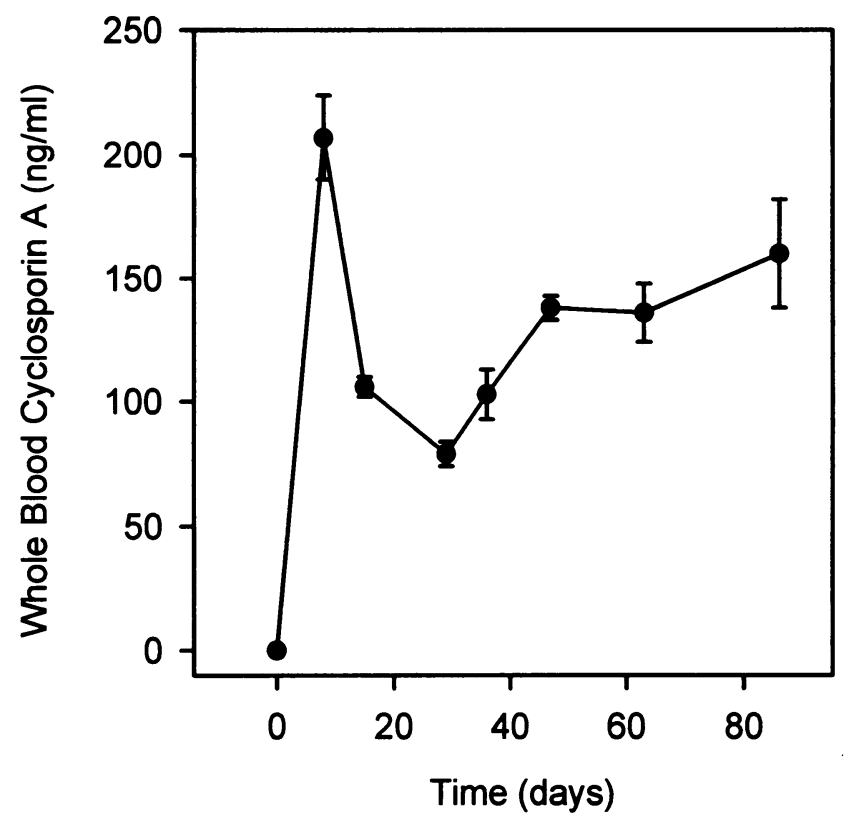

Figure 1. CyA concentrations in whole blood determined with a commercially available radioimmunoassay (Incstar Corp.). Points represent the mean concentrations of 20 samples at each interval. Bars represent the SEM.

tered subcutaneously (14). Drug concentrations in whole blood were within an immunosuppressive range throughout the study (Fig. 1).

Skin graft survival provided evidence of immunosuppression in rabbits given CyA. None of the skin grafts survived $>15 \mathrm{~d}$ in the vehicle-treated group, with acute rejection of the grafts evident as early as $8 \mathrm{~d}$, manifest as induration in all the grafts and eventual detachment of four. All grafts in immunosuppressed animals were flat and firmly adherent to the underlying subcutaneous tissues after $17 \mathrm{~d}$, with minor induration of only one graft. Therefore, skin graft survival was greatly enhanced by CyA ( $P=0.004$ Fisher's exact test $)$.

There were no significant differences between the groups with respect to the plasma concentrations of triglycerides, total cholesterol, or phospholipids. Mean ( \pm SEM) concentrations at the end of the study ( $12 \mathrm{wk}$ ) were as follows (CyA treated:Control; $\mathrm{mg} / \mathrm{dl}$ ): triglycerides $91 \pm 18: 82 \pm 14$; total cholesterol $1,272 \pm 115: 1,610 \pm 164$; phospholipids $703 \pm 87: 842 \pm 66$. Lipoprotein-cholesterol distributions were similar in all plasma samples obtained from eight rabbits in each group at day 63 of the study (Fig. 2). Plasma creatinine concentrations measured as an indicator of gross change in renal function did not change significantly throughout the study, with mean plasma concentrations remaining below $1.2 \mathrm{mg} / \mathrm{dl}$.

There was a significant increase in percentage of aortic intimal area covered by atherosclerotic lesions in the arch $(P$ $<0.01)$ and thoracic region $(P<0.05)$ of immunosuppressed animals compared with controls (Fig. 3 ). Atherosclerotic lesion coverage in the abdominal aorta was similar in both groups. Mean mass of unesterified and esterified cholesterol was increased in all regions of the aorta in the immunosuppressed animals compared with the controls, but the difference was statistically significant only in the case of unesterified cholesterol in thoracic and arch regions $(P<0.04)$.

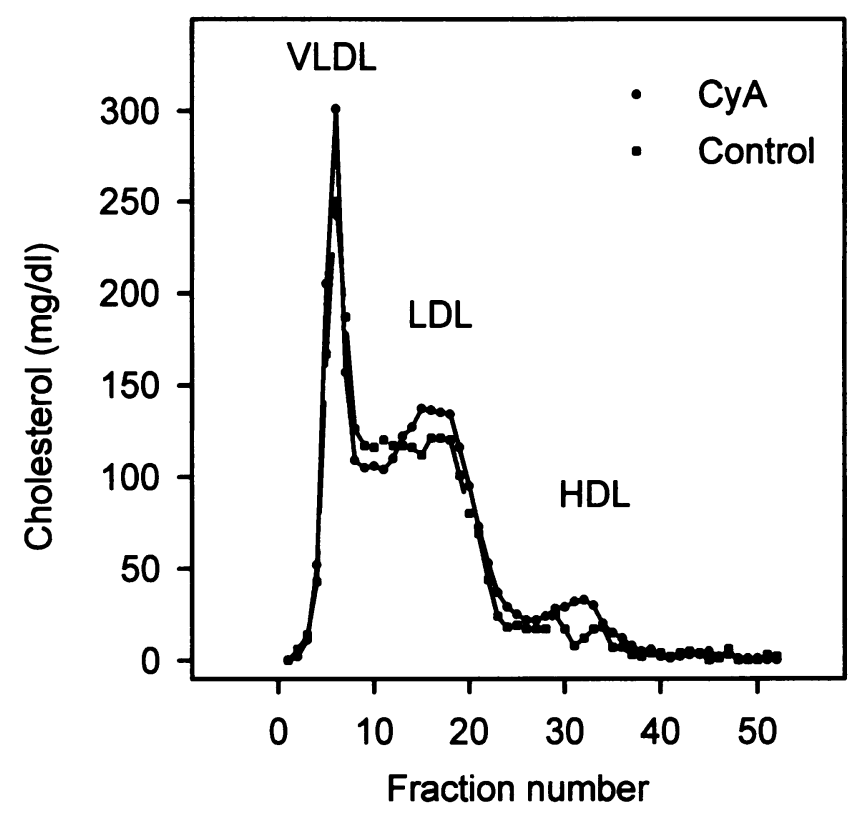

Figure 2. Lipoprotein-cholesterol distribution. Representative lipoprotein-cholesterol distributions from a CyA-treated and a control animal. FPLC profiles were obtained by the use of two Superose 6 columns connected in series. (•) CyA; ( $\bullet$ ) control.

Immunocytochemical characterization of atherosclerotic lesions from both groups demonstrated that they contained a predominance of macrophages (Fig. $4 A$ ), with relatively few smooth muscle cells (Fig. $4 \mathrm{~B}$ ). T lymphocytes were distributed in small foci, most of which were situated close to the endothelium (Fig. $4 D$ ). These observations are similar to those reported

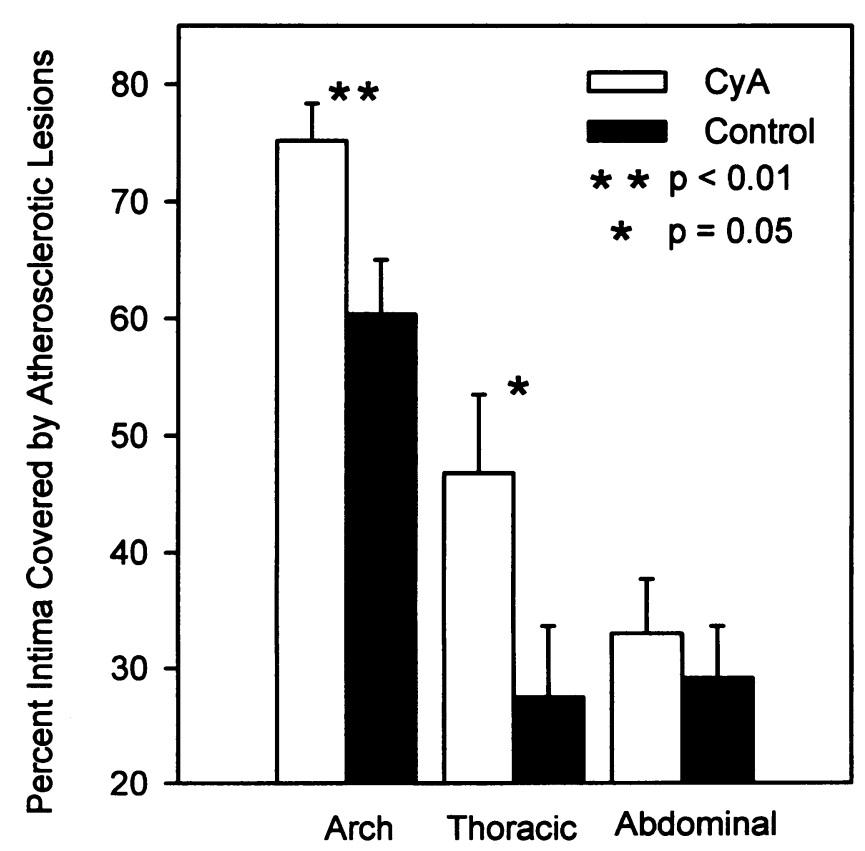

Figure 3. Percentage aortic intimal area covered by grossly discernible atherosclerotic lesions. Lesion areas were determined as described in Methods. ( $\square$ ) CyA, $n=20$; ( $\square$ ) controls, $n=16$. ${ }^{*} P<0.01 ; * P$ $=0.05$. Bars represent the SEM. 

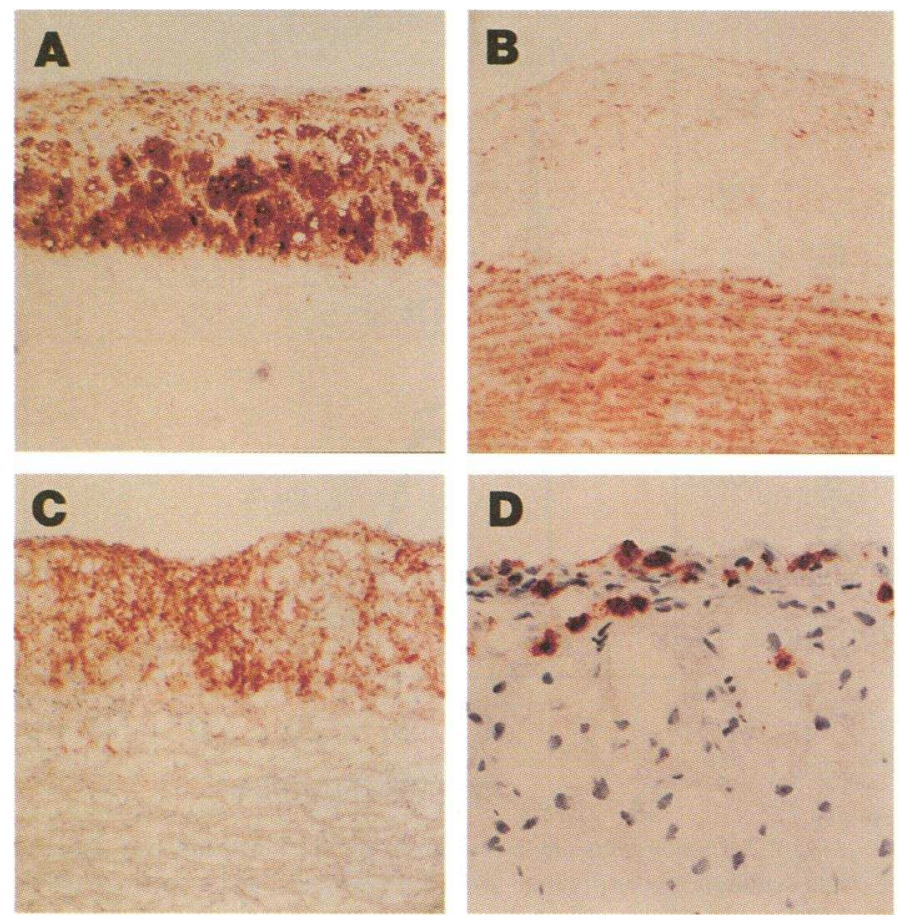

previously (5). There was no difference in the number of $\mathrm{T}$ cells immunostaining with L11/135 in the two groups. The maximum numbers of L11/135-positive cells per high-power field $\left(\times 400 ; 0.125 \mathrm{~mm}^{2}\right)$ within lesions were $9 \pm 1.5(\mathrm{CyA})$ and $10 \pm 2$ (controls), representing $15 \%$ of cell nuclei counted. $T$ lymphocytes were exclusively $\mathrm{CD} 4+$, as determined by immunostaining. Consistent with the predominance of macrophages within lesions was the MHC class II expression demonstrable on many cells, as shown by immunoreactivity to monoclonal antibody $2 \mathrm{C} 4$. No class II expression occurred in the media (Fig. $4 C$ ).

Autoantibodies to MDA-LDL were measured to assess the humoral response to atherosclerosis and to determine, in this model of atherosclerosis, if there is an association between the humoral response and the severity of atherosclerosis. Autoantibodies to MDA-LDL were present in serum from both groups of rabbits, and were detected with serum dilutions of up to $1: 30,000$. However, there were no differences in the titres of antibodies in the two groups (Fig. 5).

\section{Discussion}

Our results demonstrate that suppression of cell-mediated immune function by $\mathrm{CyA}$ administration is associated with increased severity of aortic atherosclerosis in cholesterol-fed rabbits. The observed effects of CyA-induced immunosuppression on development of atherosclerosis could not be accounted for by differences in general animal health, weight gain, plasma lipid concentrations, lipoprotein-cholesterol distributions, or renal function. Changes in severity of atherosclerosis also were not associated with discernible changes in cell populations within lesions. Furthermore, there were no differences in autoantibody titres to MDA-LDL in immunosuppressed and control animals. Suppression of cell-mediated immunity by CyA was confirmed by skin allograft survival.

The interpretation that the mechanism of enhanced athero-
Figure 4. Immunocytochemical characterization of an atherosclerotic lesion. (A) Macrophages accounted for the majority of cells within lesions, as demonstrated with immunostaining with RAM11. (B) Few smooth muscle cells are seen within lesions; the majority are confined to the media, as shown by immunostaining with HHF35. (C) Monoclonal antibody 2C4 immunostaining demonstrates that most cells in the lesions express MHC class II antigens, consistent with a predominance of macrophages. $(D) \mathrm{L} 11 / 135$ immunostaining demonstrates a cluster of $\mathrm{T}$ cells below the endothelial surface of a lesion. Magnifications are 200 for $A, B$, and $C$, and 400 for $D$.

genesis is suppression of cell-mediated immunity is based on the selective action of CyA on lymphocytes. Selectivity may be achieved by maintaining low concentrations of $\mathrm{CyA}$, since lymphocytes are comparatively inordinately sensitive to the effects of CyA. At higher concentrations, CyA may produce generalized effects since it interacts with cyclophilin A that is present in most cells $(20,21)$. Manifestations of CyA toxicity include hypertension and renal impairment, both of which can promote atherosclerosis. There was no renal impairment in the

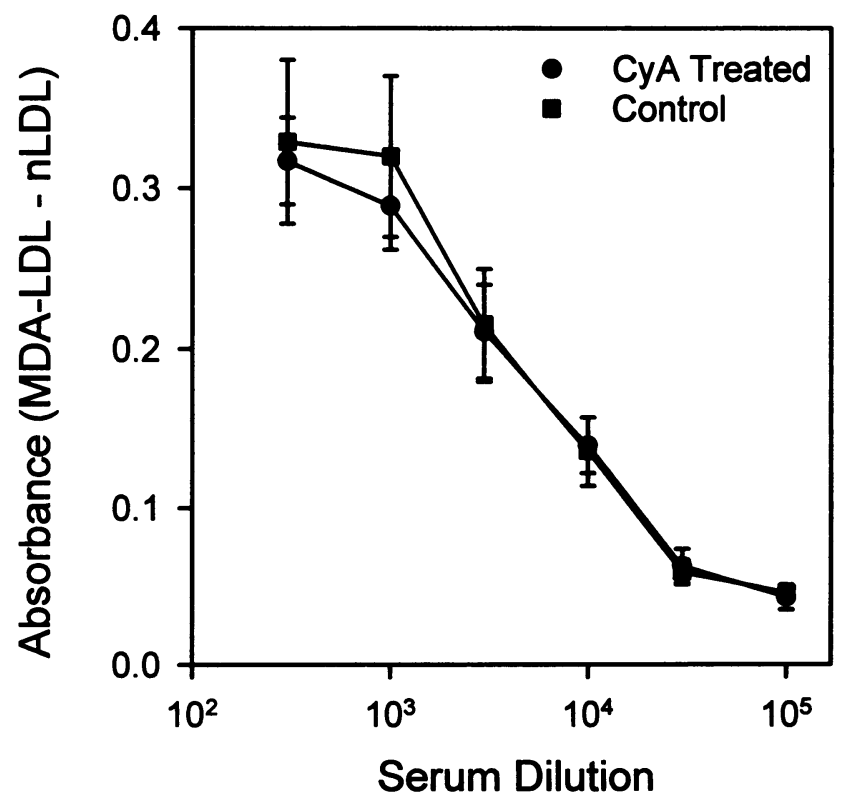

Figure 5. Autoantibodies to MDA-LDL. Antibody titres were determined as described in Methods. Titres were similar in CyA-treated and control rabbits after 12 wk of cholesterol feeding. (•) CyA, $n=6$; ( $\square$ ) controls, $n=6$. Bars represent the SEM. 
animals as judged by concentrations of serum creatinine. This confirms results of a detailed study in which extensive morphologic examination failed to reveal any overt renal toxicity at blood concentrations similar to those we used (14). CyA can increase arterial blood pressure, but this parameter was not measured because of the difficulty in obtaining meaningful data in conscious unrestrained rabbits. However, effects of CyA on arterial blood pressure and vascular reactivity are usually demonstrable at doses or modes of delivery that lead to far higher blood concentrations than attained in this study $(22,23)$. In addition, CyA-induced increases in arterial blood pressure have not been consistently observed $(24,25)$, and concentrations of the drug were far below those required to influence metabolic parameters in other cells types or to induce direct cellular toxicity (13).

The blood concentrations of CyA achieved were sufficient to cause marked inhibition of T lymphocyte activation (26), and impaired cell-mediated immunity was demonstrated by survival of allogeneic skin grafts in drug-treated rabbits. Although the drug-dosing regimen resulted in suppression of cell-mediated immunity, no gross changes in numbers of lymphocytes within atherosclerotic lesions were observed. Unlike the lymphocytic response to allogeneic skin grafts that have profound $T$ cell infiltration, the stimulus for lymphocyte adherence and migration into atherosclerotic lesions is unknown. A potential mediator of lymphocyte chemotaxis is lysophospholipids formed during oxidation of LDL (27). Oxidized LDL has been detected consistently in atherosclerotic lesions from humans and experimental animals (28). Thus, the stimulus for lymphocyte recruitment may be unaffected by $\mathrm{CyA}$, although it blunts the ability to execute cell-mediated immune responses at the site of recruitment. The lack of effect of CyA on T lymphocyte subtypes that we observed is consistent with previously published findings in mature animals, although effects have been noted in neonates $(29-31)$. CyA has also been reported to induce autoimmune disease, but this effect too has been observed in neonates only. Since the rabbits we studied were mature, no CyA-induced changes in T lymphocyte subsets or induction of autoimmunity was likely.

Other evidence indicates that the immune system may influence development of vascular disease. In immunocompromised animals, development of lesions in response to vascular injury is potentiated (32-34). Conversely, administration of IFN- $\gamma$ markedly reduces lesion growth in response to injury (35). CyA has been shown to increase the severity of atherosclerosis in cholesterol-fed C57BL/6 mice (36). However, the high daily dose of the drug $(20 \mathrm{mg} / \mathrm{kg}$ per d) used in that study greatly increased plasma cholesterol concentrations, making it difficult to ascribe the increase in lesion severity to suppression of cell-mediated immunity. Furthermore, cholesterol-fed C57BL/ 6 mice deficient in MHC class I have recently been shown to develop more severe atherosclerosis than do immunocompetent mice (37). Since no lymphocytes were detected in aortic lesions of this strain of mice (38), the mechanism of the observed effect may differ from that of the effect in rabbits and humans. Consistent with our findings, diet-induced atherosclerosis in rabbits has been shown to be reduced by parenteral administration of mixed interferons (39), and by polyinosinicpolycytidylic acid and 2-amino-5-bromo-6-phenyl-4-pyrimidinone, which raises endogenous interferon concentrations (40).

There has also been recent interest in the role of humoral immunity in the development of atherosclerosis. Evidence for a humoral-mediated effect on atherosclerosis includes the presence of immunoglobulins within lesions (41). While the targets of these antibodies have not been defined, oxidized LDL and heat shock proteins have been suggested as possibilities (10). Of interest was the lack of influence of CyA on the titre to MDA-LDL. This response is consistent with modified LDL being a $\mathrm{T}$ lymphocyte-independent antigen, although this requires further validation. Autoantibodies to MDA-LDL have been found in humans and animals $(42,43)$. In human subjects titres of these autoantibodies correlate with progression of carotid atherosclerosis (44). However, immunization of Watanabe heritable hyperlipidemic rabbits with MDA-LDL reduces severity of atherosclerosis (45). In our study, similar titres of MDA-LDL antibodies were present in the two groups despite the difference in the severity of atherosclerotic lesions. Therefore, the specific role of MDA-LDL antibodies in atherogenesis requires further examination.

The proatherogenic effect of suppression of cell-mediated immunity may be related to inhibition of secretion of specific cytokines. While lymphocytes secrete a multitude of cytokines, IFN- $\gamma$ is of particular interest because of its many functions that could influence atherogenesis. Also, this cytokine has been detected in lesions (46). The effects of IFN- $\gamma$ on decreased smooth muscle cell proliferation (35) probably contributed little to the changes in the macrophage-rich lesions observed in our study. Studies in vitro have demonstrated that IFN- $\gamma$ regulates intracellular cholesterol deposition in macrophages through regulation of scavenger receptors $(47,48)$. However, the relevance of these contradictory findings from cell culture studies to mechanisms of regulation of macrophage lipid metabolism in vivo needs to be defined. Other lymphokines may also influence the manner in which lipoproteins are modified and metabolized in the arterial wall (28). The effect of immunosuppression on development of atherosclerotic lesions in cholesterol-fed rabbits therefore may be related to attenuation of an inhibitory effect of lymphokines on cholesterol deposition within macrophages.

In summary, we have demonstrated that suppression of cellmediated immunity by administration of CyA increases the severity of atherosclerotic lesions in cholesterol-fed rabbits. Our findings highlight the need for further investigation to define the specific facet of cell-mediated immunity that is responsible for modulation of atherogenesis. We have recently demonstrated that atherosclerotic lesions in LDL-receptor $-1-$ mice possess lymphocytes (Roselaar, S. E., O. Kanagawa, and A. Daugherty, unpublished observations). This cell presence combined with transgenic and targeted gene disruption technologies to influence lymphokine secretion makes them an appropriate model for testing the hypothesis that enhanced atherogenesis during suppression of cell-mediated immunity occurs through a specific cytokine-mediated effect.

\section{Acknowledgments}

We thank Drs. Linda Wolf and Patrick Sharp for performing skin allografts; Luther Raechal and Tom Kitchens for technical assistance; Drs. Goran K. Hansson and Jay W. Heinecke for constructive criticism of the manuscript; Beth Engeszer, Debra Rateri, and Sandra Sendobry for editorial assistance; and Kelly Hall for secretarial assistance.

Alan Daugherty is an Established Investigator of the American Heart Association. 


\section{References}

1. Emeson, E. E., and A. L. Robertson. 1988. T-lymphocytes in aortic and coronary intimas: their potential role in atherogenesis. Am. J. Pathol. 130:369376.

2. Hansson, G. K., L. Jonasson, B. Lojsthed, S. Stemme, O. Kocher, and G. Gabbiani. 1988. Localization of $T$ lymphocytes and macrophages in fibrous and complicated human atherosclerotic plaques. Atherosclerosis. 72:135-141.

3. Katsuda, S., H. C. Boyd, C. Fligner, R. Ross, and A. M. Gown. 1992. Human atherosclerosis. 3. Immunocytochemical analysis of the cell composition of lesions of young adults. Am. J. Pathol. 140:907-914.

4. Jonasson, L., J. Holm, O. O. Skalli, B. Bondjers, and G. K. Hansson. 1986. Regional accumulation of $\mathrm{T}$ cells, macrophages and smooth muscle cells in human atherosclerotic plaques. Arterioscler. Thromb. 6:131-138.

5. Hansson, G. K., P. S. Seifert, G. Olsson, and G. Bondjers. 1991. Immunohistochemical detection of macrophages and T-lymphocytes in atherosclerotic lesions of cholesterol-fed rabbits. Arterioscler. Thromb. 11:745-750.

6. Munro, J. M., J. D. Van der Walt, C. S. Munro, J. A. C. Chalmers, and E. L. Cox. 1987. An immunohistochemical analysis of human aortic fatty streaks. Hum. Pathol. 18:375-380.

7. Xu, Q., G. Oberhuber, M. Gruschwitz, and G. Wick. 1990. Immunology of atherosclerosis: cellular composition and major histocompatability complex class II antigen expression in aortic intima, fatty streaks and atherosclerotic plaques in young and aged human specimens. Clin. Immunol. Immunopathol. 56:344-359.

8. Stemme, S., J. Holm, and G. K. Hansson. 1992. T lymphocytes in human atherosclerotic plaques are memory cells expressing CD45RO and integrin VLA1. Arterioscler. Thromb. 12:206-211.

9. Stemme, S., L. Rymo, and G. K. Hansson. 1991. Polyclonal origin of lymphocytes-T in human atherosclerotic plaques. Lab. Invest. 65:654-660.

10. Stemme, S., and G. K. Hansson. 1994. Immune mechanisms in atherosclerosis. Coronary Artery Dis. 5:216-222.

11. Elliot, J. F., Y. Lin, S. B. Mizel, R. C. Bleakley, D. G. Harnish, and V. T. Paetkau. 1984. Induction of interleukin 2 messenger RNA inhibited by cyclosporin A. Science. 226:1439-1441.

12. Granelli-Piperno, A., K. Inaba, and R. M. Steinman. 1984. Stimulation of lymphokine release from T lymphoblasts. J. Exp. Med. 160:1792-1802.

13. Di Padova, F. E. 1989. Pharmacology of cyclosporine (Sandimmune) V. Pharmacological effects on immune function: in vitro studies. Pharmacol Rev. 41:373-405.

14. Shah, A. K., R. C. Brundage, A. Gratwohl, and R. J. Sawchuk. 1992. Pharmacokinetic model for the subcutaneous absorption of cyclosporin in the rabbit during chronic treatment. J. Pharmaceut. Sci. 81:491-495.

15. Daugherty, A., and D. L. Rateri. 1991. Heterogeneity of very low density lipoprotein fractions: Factors influencing the ability of specific subfractions to modulate cholesterol metabolism in macrophages in vitro. Coron. Artery Dis. 2:775-787.

16. Daugherty, A., B. S. Zweifel, and G. Schonfeld. 1991. The effects of probucol on the progression of atherosclerosis in mature Watanabe heritable hyperlipidaemic rabbits. Br. J. Pharmacol. 103:1013-1018.

17. Bligh, E. G., and W. J. Dyer. 1959. A rapid method of total lipid extraction and characterization. Can. J. Physiol. Biochem. 37:911-916.

18. Ishikawa, T. T., J. MacGee, A. Morrison, and C. J. Glueck. 1974. Quantitative analysis of cholesterol in 5 to $20 \mu \mathrm{l}$ of plasma. J. Lipid Res. 15:286-291.

19. Haberland, M. E., Fogelman A. M., and P. A. Edwards. 1982. Specificity of receptor-mediated recognition of malondialdehyde modified low density lipoproteins. Proc. Natl. Acad. Sci. USA. 79:1712-1726.

20. Handschumacher, R. E., M. W. Harding, J. Rice, R. J. Drugge, and D. W. Speicher. 1984. Cyclophilin: a specific cytosolic binding protein for cyclosporin A. Science (Wash. DC). 226:544-547.

21. Koletsky, A. J., M. W. Harding, and R. E. Handschumacher. 1986. Cyclophilin: distribution and variant properties in normal and neoplastic tissues. J. Immunol. 137:1054-1059.

22. Chan, B. B. K., J. A. Kern, T. L. Flanagan, I. L. Kron, and C. G. Tribble. 1992. Effect of in vivo cyclosporine administration on endothelium-dependent responses in isolated vascular rings. Circulation. 86:SII-295-SII-299.

23. Roullet, J.-P., H. Xue, D. A. McCarron, S. Holcomb, and W. M. Bennett. 1994. Vascular mechanisms of cyclosporin-induced hypertension in the rat. $J$. Clin. Invest. 93:2244-2250.

24. Garr, M. D., and M. S. Paller. 1990. Cyclosporine augments renal but not systemic vascular reactivity. Am. J. Physiol. 258:F211-F217.

25. Textor, S. C., L. Smith-Powell, and T. Telles. 1990. Altered pressor responses to norepinephrine and ANGII during cyclosporin A administration to conscious rats. Am. J. Physiol. 258:H854-H860.

26. Rayat, G., R. Yatscoff, R. Silverman, and R. McKenna. 1993. A comparison of the immunosuppressive effects of cyclosporin $A$ and cyclosporin $G$ in vivo and in vitro. Transplantation (Baltimore). 55:623-626.

27. McMurray, H. F., S. Parthasarathy, and D. Steinberg. 1993. Oxidatively modified low density lipoprotein is a chemoattractant for human T-lymphocytes. J. Clin. Invest. 92:1004-1008.

28. Daugherty, A., and S. E. Roselaar. 1995. Lipoprotein oxidation as a mediator of atherogenesis: Insights from pharmacological studies. Cardiovasc. Res. 29:297-311.

29. Sakaguchi, S., and N. Sakaguchi. 1989. Organ-specific autoimmune disease induced in mice by elimination of $\mathrm{T}$ cell subsets. $\mathrm{V}$. Neonatal administration of cyclosporin A causes autoimmune disease. J. Immunol. 142:471-480.

30. Wick, G., P. Müller, and S. Schwarz. 1982. Effect of cyclosporin A on spontaneous autoimmune thyroiditis of obese strain chickens. Eur. J. Immunol. 12:877-881.

31. Bucy, R. P., X. X. Xu, J. Li, and G. Huang. 1993. Cyclosporin A-induced autoimmune disease in mice. J. Immunol. 151:1039-1050.

32. Jonasson, L., J. Holm, and G. K. Hansson. 1988. Cyclosporin A inhibits smooth muscle proliferation in the vascular response to injury. Proc. Natl. Acad. Sci. USA. 85:2303-2306.

33. Ferns, G., M. Reidy, and R. Ross. 1990. Vascular effects of cyclosporine A in vivo and in vitro. Am. J. Pathol. 137:403-413.

34. Hansson, G. K., J. Holm, S. Holm, Z. Fotev, H. J. Hedrich, and J. Fingerle 1991. T lymphocytes inhibit the vascular response to injury. Proc. Natl. Acad. Sci. USA. 88:10530-10534.

35. Hansson, G. K., and J. Holm. 1991. Interferon- $\gamma$ Inhibits arterial stenosis after injury. Circulation. 84:1266-1272.

36. Emeson, E. E., and M. L. Shen. 1993. Accelerated atherosclerosis in hyperlipidemic C57BL/6 mice treated with cyclosporin A. Am. J. Pathol. 142:1906-1915.

37. Fyfe, A. I., J. H. Qiao, and A. J. Lusis. 1994. Immune-deficient mice develop typical atherosclerotic fatty streaks when fed an atherogenic diet. J. Clin. Invest. 94:2516-2520.

38. Qiao, J. H., P. Z. Xie, M. C. Fishbein, J. Kreuzer, T. A. Drake, L. L. Demer, and A. J. Lusis. 1994. Pathology of atheromatous lesions in inbred and genetically engineered mice-Genetic determination of arterial calcification. Arterioscler. Thromb. 14:1480-1497.

39. Wilson, A. C., R. G. Schaub, R. C. Goldstein, and P. T. Kuo. 1990. Suppression of aortic atherosclerosis in cholesterol-fed rabbits by purified rabbit interferon. Arteriosclerosis. 10:208-214.

40. Kuo, P. T., A. C. Wilson, Goldstein R. C., and R. G. Schaub. 1984 Suppression of experimental atherosclerosis in rabbits by interferon-inducing agents. J. Am. Coll. Cardiol. 3:129-134.

41. Ylä-Herttuala, S., W. Palinski, S. W. Butler, S. Picard, D. Steinberg, and J. L. Witztum. 1994. Rabbit and human atherosclerotic lesions contain IgG that recognizes epitopes of oxidized LDL. Arterioscler. Thromb. 14:32-40.

42. Palinski, W., M. E. Rosenfeld, S. Ylä-Herttuala, G. C. Gurtner, S. A Socher, S. W. Butler, S. Parthasarathy, T. E. Carew, D. Steinberg, and J. L. Witztum. 1989. Low density lipoprotein undergoes oxidative modification in vitro. Proc. Natl. Acad. Sci. USA. 86:1372-1376.

43. Palinski, W., V. A. Ord, A. S. Plump, J. L. Breslow, D. Steinberg, and J. L. Witztum. 1994. Apo-E deficient mice are a model of lipoprotein oxidation in atherogenesis. Demonstration of oxidation specific epitopes in lesions and high titres of autoantibodies to malondialdehyde-lysine in serum. Arterioscler. Thromb. 14:605-616.

44. Salonen, J. T. S. Ylä-Hertuala, R. Yamamoto, S. Butler, H. Korpela, R. Salonen, K. Nyyssonen, W. Palinski, and J. L. Witztum. 1992. Autoantibody against oxidised LDL and progression of carotid atherosclerosis. Lancet. 339:883887.

45. Palinski, W., E. Miller, and J. L. Witztum. 1995. Immunization of low density lipoprotein (LDL) receptor-deficient rabbits with homologous malondialdehyde-modified LDL reduces atherogenesis. Proc. Natl. Acad. Sci. USA. 92:821825 .

46. Hansson, G. K., J. Holm, and L. Jonasson. 1989. Detection of activated T lymphocytes in the human atherosclerotic plaque. Am. J. Pathol. 135:169-175

47. Fogelman, A. M., J. Seager, M. E. Haberland, M. Hokom, R. Tanaka, and P. A. Edwards. 1982. Lymphocyte-conditioned medium protects human monocyte-macrophages from cholesteryl ester accumulation. Proc. Natl. Acad. Sci. USA. 79:922-926.

48. Geng, Y. J., and G. K. Hansson. 1992. Interferon- $\gamma$ inhibits scavenger receptor expression and foam cell formation in human monocyte-derived macrophages. J. Clin. Invest. 89:1322-1330. 